\title{
鏡映描写時における圧反射感度の変化：課題難易度の影響
}

\author{
札幌医科大学心理学教室 \\ 長野祐一郎
}

\section{Change in baroreflex sensitivity during mirror drawing: Effect of task difficulty}

\author{
Yuichiro NAGANO \\ Department of Psychology, Sapporo Medical University, \\ South 1 West 17, Chuo-ku, Sapporo, 060-8556, Japan
}

This study investigated the effect of encouraged active coping through changed task difficulty on baroreceptor reflex sensitivity (BRS), an index of vagal activity, by use of mirror drawing (MD) which is considered to be a typical attentional task.

This study consisted of two experiments. In both of these, heart rate (HR), systolic blood pressure (SBP), and diastolic blood pressure (DBP) were measured, and BRS was computed using the sequence scanning method. In the first experiment, 24 subjects carried out simple computerized MD. As a result, increases in HR, SBP, DBP, and BRS were observed. In the second experiment, 14 subjects performed two MD conditions. In the restricted condition, a maximum time for going round the star and a limit to the degree of deviation outside it's border were established whereas in the non-restricted condition, these parameters were not applied. Increase in HR, SBP, and DBP was more remarkable in the former than in the latter condition. BRS increased in the latter, but decreased in the former.

From the first experiment, it was revealed that simple MD fundamentally increases vagal activity. This may be attributable to the attentional nature of MD. In the second experiment, it was found that the encouragement of active coping suppressed vagal activity, even in the attentional task. These results suggested that the amount of mental effort required by the task has a large influence on the suppression of vagal activity. (Japanese Journal of Physiological Psychology and Psychophysiology, 20(3): 233-239, 2002.)

Key words: mirror drawing, attention, baroreflex sensitivity, task difficulty, mental effort

2002.6.10 受稿, 2002.11.18 受理 
【要 約】 本実験では, 注意課題の典型である鏡映描写（MD）を用い, 課題難易度の増加による能 動的対処の増強が, 迷走神経活動の指標である, 圧反射感度（BRS）に与える影響を検討した.

本研究は二つの実験から構成された。両実験において，心拍数 (HR), 収縮期血圧 (SBP), 拡張期血 圧（DBP）が計測され，BRSがシーケンス検索法により算出された. 実験 1 では24名の被験者が, コン ピュー夕化された簡潔なMDを行った。 その結果, HR, SBP, DBP, BRSに上昇が認められた. 実験 $2 て ゙$ は，14名の被験者が 2 条件のMDを実施した。一方は周回時間，逸脱の程度に制限を設けた条件で，他 方は制限の一切ない条件であった. HR, SBP, DBPの上昇は, 制限あり条件においていっそう顕著であっ た. BRSは制限なし条件においては増大したが, 制限あり条件では減少した。

実験 1 では，簡素なMDが，本来心臓迷走神経活動を増大させることを明らかにした。これは，MD の注意を伴う性質に㷌属される. 実験 2 では, 能動的対処の強調により, 注意を伴う課題であるにもか かわらず, 心臓迷走神経活動が抑制された。これらの結果は, 課題の要求する認知的努力の量が, 心臓 迷走神経活動の抑制に大きな影響をあたえることを示唆した。

\section{はじめに}

心臓迷走神経活動の指標である圧反射感度 (baroreflex seisitivity: BRS) は，一般的に精神負 荷により低下するとされている。しかし, 精神負 荷として用いられてきたのは，主として暗算課題 である（Brooks, Fox, Lopez, \& Sleight, 1978; Conway, Boon, Jones, \& Sleight, 1983; Conway, 1984; 長野, 2002; Robbe, Mulder, Ruddel, Langewitz, Veldman, \& Mulder, 1987; Steptoe \& Sawada, 1989; 田中・澤田, 1994; 田中・澤田・藤井, 1994)。寒 冷昇圧課題を用いたSteptoe \& Sawada (1989), 騷音ストレスを用いたSawada（1993）, 反応時間 課題を用いた田中ら（1994）などの，暗算以外を 用いた例では, 明確な低下が認められない場合も 多い. 加えて, 最近の長野 (2002) の研究では, 同じ暗算課題であっても, 課題内容の提示がコン ピュータ画面への注意を伴う場合, BRSに明確な 低下を認めなかった。課題が注意を伴う場合心臓 迷走神経活動は立進する可能性がある（Berntson, Cacioppo \& Fieldstone, 1996; Jennings, 1992; Lacey \& Lacey, 1974). その典型とみなされるのが, 課 題遂行時に星型図形への強い注意が生じる鏡映描 写である。実際, 鏡映描写課題中の呼吸性不整脈 を検討したInamori \& Nishimura（1995）は, 課題 遂行中に呼吸性不整脈の増大を見出し, 心臓迷走 神経活動の六進から心拍数が減少することを指摘 した。鏡映描写課題中のBRSの変化を検討するな らば, BRSは呼吸性不整脈と同様に心臓迷走神経 活動の指標であるだけでなく，呼吸の影響も受け
にくいため（田中・澤田, 1994), 呼吸性不整脈 以上に明瞭な増大が認められてもおかしくはある まい.

しかし，同じくBerntson et al. (1996) によれ ば, 注意を伴う課題のうち, ある種のものは迷走 神経活動を亢進させる可能性があるものの, しば しば能動的対処や認知的努力を要求して, 交感神 経系の反応性を増大させるため, 迷走神経活動の 克進を妨害するという潜在的な複雑さを持ってい る.したがって, 鏡映描写課題は強い注意を伴う 課題であり, 本来は心臓迷走神経活動を六進させ るが，それになんらかの付加条件が加わって能動 的対処の側面が強まると, Berntson et al. (1996) の指摘するような状態を招くことも想定される. Steptoe, Fieldman, Evans \& Perry（1993）の鏡映描 写課題で, BRSの低下が報告されたのには，こう した事情があるのかもしれない.

そこで, 能動的対処を強めうる要因であるが, 反応-成果の随伴性 (response-outcome contingency), 課題の新奇性, 遂行結果のフィードバッ クの有無, 課題の難易度等が上げられる（Obrist, 1981; Light \& Obrist, 1983). 中でも, 多くの研究 において検討されてきたのは課題の難易度が及ほ す影響である。ショック回避型の反応時間課題を 用いたObrist, Gaebelein, Teller, Langer, Grignolo, Light \& McCubbin（1978）, 金銭報酬を伴う反応 時間課題を用いたLight \& Obrist (1983), アナグ ラム課題を用いたvan Schijndel, De Mey \& Naring (1984）, 記憶課題を用いたWright, Contrada \& 
Patane (1986)，対人説得課題を用いた Smith, Baldwin \& Christeinsen（1990）では，いずれも課 題が中程度に難しい場合, 能動的対処は強めら れ，心臓血管反応性が最大になると報告されてい る.したがって, 強い注意を伴う鏡映描写課題で あっても，難易度の調節により能動的対処の側面 が強調されれば, 心臟迷走神経活動は抑制される 可能性がある.

そこで本研究では, 第一に付加条件をなるべく なくした鏡映描写課題を用い, 課題それ自体が心 臓迷走神経活動の指標であるBRSに与える影響を 検討した，次いで第二に，課題難易度を増し，能 動的対処の側面を強めることにより, 鏡映描写課 題中の心臓血管反応がどのように推移するかを, やはりBRSを中心に検討した。

\section{実験 1}

\section{方法}

被験者は健常な女子大学生24名（平均年齢21.3 歳）であった。鏡映描写課題は，コンピュー夕上 で実現されたものを用いた。被験者はシールド ルームの中で椅子に腰掛け, 眼前約 $80 \mathrm{~cm}$ の位置 にあるディスプレイ上に表示された星型図形をマ ウスでなぞるように教示された、マウスの動きと 画面上のカーソルの動きは, 左右のみが反転して おり，上下はそのままであった。星型図形には カーソルの軌跡が表示された. ディスプレイ画面 上での星型図形の線の太さは約 $6 \mathrm{~mm}$ であり, 星 型図形の一辺の長さは約 $65 \mathrm{~mm}$ であった。はみた した場合はもとの位置まで戻るように，また一周 した場合はそのままなぞりつづけるよう教示し，

「なるべく早く正確に」などの教示は行わなかっ た. 全ての被験者は, 5 分間の安静の後, 鏡映描 写課題を 3 分間行った。

\section{実験 2}

被験者は健常な大学生14名（男子 2 名, 女子 12 名，平均年齢22.5歳）であった。用いた課題拉よ び実施環境は実験 1 とほぼ同様であったが, 星型 図形の一辺の長さが約 $50 \mathrm{~mm}$ である点のみ異なっ ていた，星型図形は一周する毎に自動的に再描画 された。

被験者は実験開始前に, 逸脱回数 3 回以内で星
型を一周できるようになるまで練習した。制限の 有無により 2 条件が設定され, 制限なし条件では 被験者はなるべく正確に自分のペースで星型をな ぞるように教示され, 制限あり条件では, 被験者 はディスプレイの左上に表示された制限時間内に 星型を一周することが求められた。

制限時間は, 練習時の最終周回時に要した時間 を基準に設定された。すなわち，課題開始時には 練習最終周回時の $80 \%$ に設定され，これが時間経 過と共に短縮されて，最終的に50\%の長さとなる ようプログラムにより自動的に調節された。ささら に制限あり条件では，ディスプレイの下方に逸脱 すると減少するバーグラフが表示され，これがな くならない様に一周するよう教示された。なお， 時間制限, 逸脱制限は教示のみで, 条件を満たす ことができない場合でも特に罰刺激等は与えるこ とがなく，金銭報酬とも無関連であった.

全ての被験者が, 制限あり, 制限なしの両条件 を実施した。 5 分間の安静期の後, 制限ありもし くは制限なしのいずれかの条件で鏡映描写課題を 行い, その直後に再び 5 分間の安静期間をとり， その後条件を変えて鏡映描写を再び行った．実行 する条件の順序を被験者毎に入れ替え, 条件の順 序効果を相殺した。

\section{装 置}

日本電気三栄製ポリグラフシステム360を介し て, 心電図および血圧（日本コーリンJENTOW 7700）が連続的に記録された。生体情報は16bit の分解能, $1000 \mathrm{~Hz}$ の精度で $\mathrm{AD}$ 変換された後, コ ンピュータのハードディスクに記録された。 Lab VIEW言語を用いたソフトウェアにより，心電図 波形から心拍間隔（inter beat interval: IBI, ms）お よび心拍数（heart rate: HR, bpm）の算出が, 連 続血圧波形から一拍毎に収縮期血圧（systolic blood pressure: SBP, mmHg)，および拡張期血圧 (diastolic blood pressure: DBP, $\mathrm{mmHg}$ ) の算出が 行われた. BRSは, 独自に開発したソフトウェア を用い, Bertinieriグループのシーケンス検索法 (Bertinieri, di Rienzo, Cavallazzi, Ferrari, Pedotti, \& Mancia，1985）に基づき，算出した。具体的に は，SBPの上昇（または下降）が 3 心拍以上連続 し，しかもこれと同じ心周期でIBIが 3 心拍以上 
Table 1 Mean scores and standerd deviation of cardiovascular response during rest and mirror drawing.

\begin{tabular}{ccccc}
\hline & $\begin{array}{c}\text { HR } \\
(\mathrm{bpm})\end{array}$ & $\begin{array}{c}\text { SBP } \\
(\mathrm{mmHg})\end{array}$ & $\begin{array}{c}\text { DBP } \\
(\mathrm{mmHg})\end{array}$ & $\begin{array}{c}\text { BRS } \\
(\mathrm{ms} / \mathrm{mmHg})\end{array}$ \\
\hline rest & $76.4(10.7)$ & $103.9(8.4)$ & $56.0(8.0)$ & $14.7(5.9)$ \\
task & $81.9(13.9)$ & $118.1(15.2)$ & $64.5(9.7)$ & $16.8(6.9)$ \\
\hline
\end{tabular}

Table 2 Mean scores and standerd deviation of cardiovascular response during rest and mirror drawing, in restricted and non-restricted condition.

\begin{tabular}{ccccccccc}
\hline & \multicolumn{2}{c}{$\mathrm{HR}(\mathrm{bpm})$} & \multicolumn{2}{c}{$\mathrm{SBP}(\mathrm{mmHg})$} & \multicolumn{2}{c}{$\mathrm{DBP}(\mathrm{mmHg})$} & \multicolumn{2}{c}{$\mathrm{BRS}(\mathrm{ms} / \mathrm{mmHg})$} \\
\hline & restricted & non-restricted & restricted & non-restricted & restricted & non-restricted & restricted & non-restricted \\
\hline rest & $64.5(8.1)$ & $64.6(7.7)$ & $106.2(6.7)$ & $109.9(12.2)$ & $53.5(6.7)$ & $57.7(7.6)$ & $21.0(7.4)$ & $18.2(4.5)$ \\
task & $69.9(8.2)$ & $66.9(6.5)$ & $112.6(9.5)$ & $112.1(11.9)$ & $56.8(6.9)$ & $58.7(8.4)$ & $17.7(4.3)$ & $20.3(5.8)$ \\
\hline
\end{tabular}

延長（または短縮）するような特別のシーケンス をコンピュータで検索し, 各シーケンス内のSBP とIBIの回帰直線の傾き $(\mathrm{ms} / \mathrm{mmHg})$ を計算し た. BRSはその単位からして, $\mathrm{SBPが} 1 \mathrm{mmHg}$ 上 昇（または下降）するとき，IBIが何 $\mathrm{ms}$ 延長（ま たは短縮）するかを表していると理解される.

\section{実験 1}

\section{結 果}

BRSを算出する際に, 十分な数のシーケンス （1分あたり 5 シーケンス）が得られなかった被 験者を除外した結果, 有効被験者数は17名となっ た. 各指標における, 安静期最後の 3 分間の平均 值, 課題期 3 分間の平均值をTable 1 に示した。 これらの平均值に関し, 安静期と課題期の間に差 があるかを繰り返しのある $\mathrm{t}$ 検定を用いて検討し た. $\operatorname{HR}(\mathrm{t}(16)=2.72, \mathrm{p}<.05), \operatorname{SBP}(\mathrm{t}(16)=5.31$, $\mathrm{p}<.01), \operatorname{DBP}(\mathrm{t}(16)=3.52, \mathrm{p}<.01)$ から, これら の指標では直前の安静期に比べ，鏡映描写課題中 に統計的に有意な上昇が認められた。BRSは, 直 前の安静期に比べ高い傾向（ $\mathrm{t}(16)=2.08, \mathrm{p}<.10)$ が認められた。安静時におけるHRとBRSの相関 は-.83 ( $\mathrm{n}=17, \mathrm{p}<.01)$ ，鏡映描写課題時のHRとBRS のそれは-.52（n=17, p<.05）であり, 課題実行中 は安静期に比べHRとBRSの相関が低かったもの の，その差は統計的に有意ではなかった。

\section{実験 2}

BRSの算出に際し，実験 1 と同様の基準で被験 者を除外した結果, 有効被験者数は11名となっ た. 各指標における安静期最後の 3 分間の平均

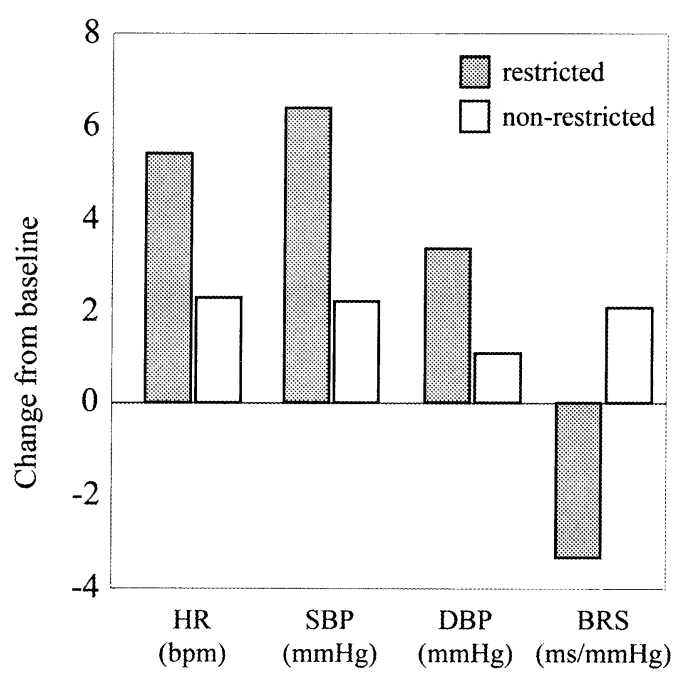

Fig. 1 Cardiovascular response to the mirror drawing task in restricted and non-restricted condition. Significant interaction was found only in BRS.

值, 課題期 3 分間の平均值を条件別にTable 2 に 示した。また，各指標の安静期からの変化量を， 条件別にFig. 1 に示した。

HRに関し，条件（制限あり，制限なし）×期 間（安静期，課題期）で繰り返しのある分散分析 を行ったところ，期間の主効果 $(F(1 / 13)=16.02$, $\mathrm{p}<.01)$ ，および，交互作用 $(\mathrm{F}(1 / 13)=9.77, \mathrm{p}<.01)$ が有意であった。安静期にくらべ課題期でHRの 上昇がみとめられ，さらに単純主効果を調べたと ころ, 両条件ともに課題期における上昇が認めら れたが（制限あり条件はp $<.01 ，$ 制限なし条件は $\mathrm{p}<.05)$, さらに課題期において両条件間に差が認 められ $(\mathrm{p}<.05), \mathrm{HR}$ の上昇の度合いは，制限あ り条件においてより大きいことが明らかになっ 
た。同様に分散分析を行ったところ，SBPに関し ては期間の主効果 $(\mathrm{F}(1 / 13)=22.09, \mathrm{p}<.01)$ ，およ び，交互作用 $(F(1 / 13)=7.86, p<.05)$ が有意, DB $\mathrm{P}$ に関しては期間の主効果 $(\mathrm{F}(1 / 13)=9.36, \mathrm{p}<.01)$, および，交互作用 $(\mathrm{F}(1 / 13)=5.41, \mathrm{p}<.05)$ が有意 であった，SBP, DBPともに安静期に比べ課題期 で上昇したが，下位検定の結果，SBPに関しては 安静期, 課題期ともに条件間で有意な差は認めら れなかった。 DBPに関して単純主効果を調べたと ころ，制限あり条件においてのみ有意な上昇 （p<.01）を認めた．BRSに関しては，交互作用の み $(\mathrm{F}(1 / 10)=5.70, \mathrm{p}<.05)$ が有意であり, 単純主 効果を調べたところ, 制限なし条件では直前の安 静期に比べ上昇, 制限あり条件においては, 直前 の安静期に比べ減少することが示された（ともに $\mathrm{p}<.10)$.

\section{考察}

実験 1 は，とくに付加的な条件設定がないこと から，標準的な鏡映描写課題の結果と考えられ る. 課題期における HR, SBP, DBPは安静期に比 べ有意に上昇したが，同時にBRSも $14.7 \mathrm{~ms} / \mathrm{mmHg}$ から $16.8 \mathrm{~ms} / \mathrm{mmHg}$ へわずかに上昇しており，この 変動は $10 \%$ 水準ではあるが, 統計的に有意であっ た。また，実験 2 の制限なし条件においても， $\mathrm{BRS} 17.7 \mathrm{~ms} / \mathrm{mmHg}$ から $20.3 \mathrm{~ms} / \mathrm{mmHg}$ へ上昇して おり,これらの結果から, とくに付加的な条件を 設定しない鏡映描写課題においては，心臓迷走神 経活動はむしろ六進する傾向にあることが示唆さ れた. Inamori \& Nishimura (1995) と一致する結 果である。

HRは，実験 1 においても実験 2 の制限なし条 件においてもわずかに上昇しており，この結果は BRSの上昇と矛盾するように思われる。心臟は交 感神経と迷走神経両者の支配を受けており，前者 の活動六進はHRを上昇させ，後者は逆の効果を 持つ. 両神経系は身体にもたらす影響が正反対で あり, 多くの場合は相反する方向へ相補的な変化 を生じるが，条件によっては同時に㐫進する場合 があることが知られている（Berntson, Cacioppo, Binkley, Uchino, Quigley, \& Fieldstone 1994; Koizumi \& Kollai, 1992). したがって, 迷走神経
活動にえ進がみとめられる場合でも交感神経活動 の充進が同時に生じたならば，HRは上昇しうる。 とりあえず，実験 1 の鏡映描写課題に関しては, 迷走神経活動の亢進がごくわずかであるため, 同 時に生じた交感神経活動の充進に上書きされ, 結 果としてHRの上昇を生じたと考えてよいだろう.

このことと関連して, 実験 1 の安静期における HR と BRSの相関が-.83であることは, 安静期の HRがおおむね心臓迷走神経活動を反映する事実 からして，かなりの程度予測可能な結果である. しかし, 課題期における両者の相関が-.52にまで 低下したことは，そのときのHRが，もはやBRS だけからは予測しがたいことを示唆している。す なわち, 課題期におけるHRには, 交感神経の活 動が関与している可能性が推定される.

実験 2 においても, 課題期にHR, SBP, DBPの 上昇は認めたが, 実験 1 における同指標の上昇と 比べ，時間制限のありなしにかかわらず軽微で あった．実験 2 では相当量の練習を行った後の計 測であったため, 課題の持つ新奇性の影響は失わ れ、このような差が生じたものと思われる。たた し上昇の度合いは制限あり条件において明らかに 大きく，課題難易度の上昇が影響した結果である と理解できる。興味深いことに，BRSに関しては 交互作用が認められ，制限あり条件と制限なし条 件で, 課題期での変化の方向が逆転していた。こ のことを実験 1 の結果と合わせて考えると，鏡映 描写課題そのものはわずかに心臟迷走神経活動の 亢進を引き起こすが, 課題の難易度が増し能動的 対処の側面が強化されると，その影響により心臓 迷走神経活動が抑制されたと理解できる。

能動的対処に㧍ける課題難易度の違いは, 認知 的努力のいかんに影響を与えるものとして，検討 が加えられてきた（Bongard, 1995; Gerin, Pieper, Marchese \& Pickering, 1992; Light, 1981; Lovallo, Wilson, Pincomb, Edwards, Tompkins \& Brackett, 1985; Manuck, Harvey, Lechleiter \& Neal, 1978; Obrist et al., 1978). 反応-成果の随伴性があり, なおかつ, 課題がある程度難しい場合に, 心臟血 管反応性が最大になる事を示す一連の結果は, そ の背後に認知的努力の高まりが存在する事を予測 させる、実際，Bongard（1995）の周到な二重課 
題パラダイムにより，コントロールが存在する場 合はより多くの認知的努力が引き出され，同時に 心臓血管反応が増加することが示された。これら の知見を踏まえると，本研究の制限あり条件にお けるHR, SBP, DBPの上昇, および心臓迷走神経 活動の抑制も，課題難易度の上昇に誘発された認 知的努力の増加を反映したものと理解してよいた ろう。

本実験と直接に比較可能な研究である既述の Steptoe et al. (1993) では，鏡映描写課題中に心 臓迷走神経活動の抑制されたことが報告されてい る.この研究では, 課題を自由なペースで遂行す る群と，ペースを外的に規定される群とを設けて おり, HRの上昇, BRSの減少は後者においてよ り顕著に生じたとしている。外的なぺース規定 は, 時間制限という点で本実験 2 における制限あ り条件と類似しており，したがって心臓血管反応 性の増大は, 本実験 2 の場合と同様に, 課題が要 求する認知的な努力の増大に起因していたと考え られる。加えて, 本実験ではコンピュータによる 鏡映描写課題を用いたが, Steptoe et al. (1993) では, 鉄筆が星型経路から外れると大きなブザー 音が鳴る形式のものであった。こうした，ブザー 音による警告は, フィードバック刺激となって, やはり能動的対処の側面を強め, 認知的努力を いっそう増大させたと予測される。本実験の制限 なし条件に相当する, 自由ペース課題にあってさ え，BRSが抑制方向へ変化したのは，そのような 認知的努力の高まりを反映したものと考えられ る。

結論として, 本実験 1 では, 付加条件のない鏡 映描写課題において, BRSの上昇する傾向が認め られ，鏡映描写課題のような，一般にストレス負 荷と考えられている課題であっても，BRSは上昇 する場合のあることが示された。次いで，本実験 2 , および比較可能な他研究の結果から, 課題の 難易度増加に伴い生じる認知的努力の増加は, 心 臓血管系にいっそう顕著な反応を生じさせ，とく に心臓迷走神経活動に対しては抑制的な変化をも たらすことが示唆された。鏡映描写課題のよう に, 本来心臟迷走神経活動を立進させる性質の課 題であっても, 認知的努力の増加によりその性質
は上書きされむしろ迷走神経活動の抑制をきた す。こうして, 認知的努力の増加と心臓迷走神経 活動の抑制との間には, 相当に堅固な関係が存在 すると考えて良いだろう。

なお, 本実験では, 同じ課題であっても, 課題 の要求する認知的努力の量, 課題の持つ新奇性に より，心臓血管系の反応は大きく異なることが示 唆された。これらの要素は, 実験結果に無視でき ないほどの大きな影響を与える危険性がある。刺 激の設定や手続きの微妙な違いにより暗黙の内に 大きく変化し，とくに認知的努力に関しては，実 験者の意図とは関係なく, 大きく変わってしまう 可能性があると思われる。したがって, 課題が要 求する認知的努力の程度を常に, あるいは, 積極 的に統制するためにも, 課題成績の分析や，質問 紙による主観的評価を平行して試みることが重要 であろう。

\section{謝辞}

執筆にあたりご指導下さいました札幌医科大学 の澤田幸展先生, 田中豪一先生にこの場を借りて 御礼申し上げます。

\section{引用文献}

Berntson, G. G., Cacioppo, J. T., Binkley, P. F., Uchino, B. N., Quigley, K. S., \& Fieldstone, A. 1994 Autonomic cardiac control. III. Psychological stress and cardiac response in autonomic space as revealed by pharmacological blockades. Psychophysiology, 31, 599-608.

Berntson, G. G., Cacioppo, J. T., \& Fieldstone, A. 1996 Illusions, arithmetic, and the bidirectional modulation of vagal control of the heart. Biological Psychology, 44, 1 17.

Bertinieri, G., di Rienzo, M., Cavallazzi, A., Ferrari, A. U., Pedotti, A., \& Mancia, G. 1985 A new approach to analysis of the arterial baroreflex. Journal of Hypertension Supplement, 3, S79-81.

Bongard, S. 1995 Mental effort during active and passive coping: a dual-task analysis. Psychophysiology, 32, $242-$ 248.

Brooks, D., Fox, P., Lopez, R., \& Sleight, P. 1978 The effect of mental arithmetic on blood pressure variability and baroreflex sensitivity in man [proceedings]. Journal of Physiology, 280, 75P-76P.

Conway, J., Boon, N., Jones, J. V., \& Sleight, P. 1983 Involvement of the baroreceptor reflexes in the changes in blood pressure with sleep and mental arousal. 
Hypertension, 5 , 746-748.

Conway, J. 1984 Hemodynamic aspects of essential hypertension in humans. Physiological Reviews, 64, 617-660.

Gerin, W., Pieper, C., Marchese, L., \& Pickering, T. G. 1992 The multi-dimensional nature of active coping: differential effects of effort and enhanced control on cardiovascular reactivity. Psychosomatic Medicine, 54, 707-719.

Inamori, Y., \& Nishimura, K. 1995 Cardiovascular changes during different mental load tasks. Japanese Journal of Biofeedback Research, 22, 19-22.

Jennings, J. R. 1992 Is it important that the mind is in a body? Inhibition and the heart. Psychophysiology, 29, 369383.

Koizumi, K., \& Kollai, M. 1992 Multiple modes of operation of cardiac autonomic control: development of the ideas from Cannon and Brooks to the present. Journal of the Autonomic Nervous System, 41, 19-29.

Lacey, B. C., \& Lacey, J. I. 1974 Studies of heart rate and other bodily processes in sensorimotor behavior. In P. A. Obrist, A. H. Black, J. Brenner and L. V. DiCara(Eds.), Cardiovascular Psychophysiology. Chicago: Aldine. Pp. 538-564.

Light, K. C. 1981 Young Psychophysiologist Award address, 1980. Cardiovascular responses to effortful active coping: implications for the role of stress in hypertension development. Psychophysiology, 18, 216-225.

Light, K. C., \& Obrist, P. A. 1983 Task difficulty, heart rate reactivity, and cardiovascular responses to an appetitive reaction time task. Psychophysiology, 20, 301-312.

Lovallo, W. R., Wilson, M. F., Pincomb, G. A., Edwards, G. L., Tompkins, P., \& Brackett, D. J. 1985 Activation patterns to aversive stimulation in man: passive exposure versus effort to control. Psychophysiology, 22, 283-291.

Manuck, S. B., Harvey, A. H., Lechleiter, S. L., \& Neal, S. K. 1978 Effects of coping on blood pressure responses to threat of aversive stimulation. Psychophysiology, 15, 544549.

長野祐一郎 2002 能動的対処は圧反射感度を抑制する か 生理心理学と精神生理学, 20, 1-8
Obrist, P. A., Gaebelein, C. J., Teller, E. S., Langer, A. W., Grignolo, A., Light, K. C., \& McCubbin, J. A. 1978 The relationship among heart rate, caratid $\mathrm{dP} / \mathrm{dt}$, and blood pressure in humans as a function of the type of stress. Psychophysiology, 15, 102-115.

Obrist, P. A. 1981 Cardiovascular psychophysiology. New York: Plenum Press.

Robbe, H. W., Mulder, L. J., Ruddel, H., Langewitz, W. A., Veldman, J. B., \& Mulder, G. 1987 Assessment of baroreceptor reflex sensitivity by means of spectral analysis. Hypertension, 10, 538-543.

Sawada, Y. 1993 Reproducible increases in blood pressure during intermittent noise exposure: underlying haemodynamic mechanisms specific to passive coping. European Journal of Applied Physiology \& Occupational Physiology, 67, 367-374.

Smith, T. W., Baldwin, M., \& Christensen, A. J. 1990 Interpersonal influence as active coping: effects of task difficulty on cardiovascular reactivity. Psychophysiology, 27, 429-437.

Steptoe, A., \& Sawada, Y. 1989 Assessment of baroreceptor reflex function during mental stress and relaxation. Psychophysiology, 26, 140-147.

Steptoe, A., Fieldman, G., Evans, O., \& Perry, L. 1993 Control over work pace, job strain and cardiovascular responses in middle-aged men. Journal of Hypertension, 11, 751-759.

van Schijndel, M., De Mey, H., \& Naring, G. 1984 Effects of behavioral control and type A behavior on cardiovascular responses. Psychophysiology, 21, 501-509.

田中豪一・澤田幸展 1994 呼吸の影響からみた呼吸性 洞性不整脈と圧受容体反射感受性の比較 心身医学, 34, 473-479.

田中豪一・澤田幸展・藤井力夫 1994 ストレス作業時 の迷走神経抑制 心理学研究, 65, 9-17.

Wright, R. A., Contrada, R. J., \& Patane, M. J. 1986 Task difficulty, cardiovascular response, and the magnitude of goal valence. Journal of Personality \& Social Psychology, $51,837-843$ 